\title{
The creation and trial of a serious game to support teaching and learning of professional psychology competencies in postgraduate programs
}

\author{
Gillian McGregor and Emma Bartle \\ The University of Queensland
}

\begin{abstract}
The education of healthcare professionals is critical for the safe delivery of services to patients (Ricciardi \& de Paolis, 2014). Postgraduate psychology students undertaking a professional degree encounter a steep learning curve when transitioning from theoretical knowledge to professional practice. This beginning student stage of development is fraught with anxiety and high-stress levels, and has implications for both student and client wellbeing (Skovholt \& Ronnestad, 2003). Successful navigation of this phase is critical to psychology graduate competence and employability, with potentially lasting consequences for psychologists' perceptions of self-efficacy and career trajectory (De Stefano et al., 2007; Skovholt \& Ronnestad, 2003). Serious games in health provide the potential for safe practice opportunities in an engaging and entertaining manner (Hawn, 2009; Knight et al., 2010). The author developed a serious game with the intention of providing postgraduate professional psychology students with increased and more convenient opportunity to practice psychological competencies. This paper synthesises game design theory into a prototype for educators to provide innovative solutions in a health context. It contributes to the body of research determining the efficacy of games in educational contexts and advances knowledge in the use of simulation pedagogies.
\end{abstract}

\section{Background}

Students embarking on a Professional Master's of Psychology degree are required to enter field placements within the first months of commencing the program. These field placements are a central aspect of the training and are the forum in which students' first have the opportunity to begin transitioning their theoretical knowledge to clinical competence. Further, these early real-world experiences are when students begin developing their professional identity and their experiences on field placement have the potential to influence how they will view themselves as practitioners and the therapeutic process as a whole (De Stefano et al., 2007; Howard, Inman, \& Altman, 2006). Given this, it is important that field placements are scaffolded appropriately to ensure the students' overall learning experience contributes positively towards their studies, and hence their development, as a practitioner.

It is known that student anxiety levels are typically high during this developmental period, and this can hinder how effectively students learn and apply their skills to clients (patients). An early negative experience like this can erode the fledgling sense of competence trainees may possess and lead to early career burnout (De Stefano et al., 2007; Melton, Nofzinger-Collins, Wynne, \& Susman, 2005; Skovholt \& Ronnestad, 2003). Ideally, programs should include learning activities that support students' transition into field placements and sequentially develop their professional clinical skills, such as strategies for managing anxiety in the clinical environment. However, the teaching of these professional clinical skills is limited by time, resources, and logistical factors, as is often the case in health-related training (Knight et al., 2010). Professional psychology postgraduate programs often provide students with an intensive immersion during orientation week, where they are taught the early competencies required before commencing field placement. These include how to conduct an intake interview, undertake a suicide risk assessment, and navigate an ethical dilemma. Traditionally these clinical competencies are taught using linear methods of instruction and role-playing of scenarios with peers. Such activities are typically time pressured, with students aware of the evaluative presence of staff and unfamiliar peers. Additionally, in the short period of time for orientation, students are also inundated with administrative information and tasks for their field placement. Anecdotal evidence of these early training activities indicates students feel overwhelmed with content and their capacity for retention of information at this time is limited. Due to timetable and life pressures, students find it difficult to find time to practice these skills in safe, relatively unpressurised environments outside of the immersion period. Certainly, stress can disrupt the process of learning and retention of information (Mendl, 1999). A need exists for instructors to find new instructional strategies to 
develop students' early clinical competencies in a safe environment, which reduces their stress levels and supports achievement of learning outcomes on placement.

\section{Serious games and learning}

Games have been used for centuries to convey knowledge and skills through experience (Crocco, Offenholley, \& Hernandez, 2016; Lewis, 2007). Advances in technology and the availability of mobile devices have enabled game-based approaches to become increasingly accessible for the public and easier to implement in a range of contexts, such as education (Lewis, 2007). As more people are exposed to mobile games, attention has shifted to the possibility of using games for purposes other than pure entertainment. Serious games are defined as games which have a primary purpose of educating and training players, whilst entertaining them at the same time (Stokes, 2005).

Bergeron (2006) defines serious games as computer applications which are fun and engaging whilst providing the player with a goal to work towards. It is through this the player acquires knowledge and skills which have use in the real world (Mautone, Spiker, \& Karp, 2008). Serious games create a setting whereby players follow a set of rules as they actively participate and engage with challenges to attain prescribed goals and progress through the game (Clochesy, Buchner, Hickman, Pinto, \& Znamenak, 2015). Serious games can be used to train skills and impart knowledge, and have the potential to support teaching and learning as well as benefit the learning of professional skills (Clochesy et al., 2015; Hawn, 2009). This implies that in a health professional education context, serious games have the potential to support students to develop professional clinical skills in an engaging manner. Serious games are designed to enhance teaching and learning by providing an environment which enhances the receptivity of the learner to the message being communicated. They achieve this by enabling the information to be communicated more implicitly through the mechanism of play and the use of features which promote affective arousal and thus enhance engagement with material presented (Malone, 1980; Randel, Morris, Wetzel, \& Whitehall, 1992). This allows for improved rates of learning efficiency around the acquisition and retention of knowledge. Learners can tailor their learning with input into the pace and experience in a student-led style of learning (Dror, 2008). This contrasts with traditional methods of learning where the lecturer is in control of the experience (lecturer centred). In the former scenario, the student engages directly with the material and experiences an active approach (Ricciardi \& de Paolis, 2014). This increased engagement sets the scene for authentic and quality learning experiences (Coates, 2005). Serious games in healthcare education thus have the potential to enhance engagement and create a successful starting point of learning from a place of interest and motivation (Klauer \& Leutner, 2012).

With technological advances, synthetic environments have the potential to address training concerns in healthcare, including patient safety, time taken for training, and student engagement and motivation (Gee, 2003; Susi, Johannesson, \& Backlund, 2007). Historically, simulations have been used in some healthcare areas, however, the lack of entertainment features may result in difficulties in motivating and engaging students (Knight et al., 2010). Serious games have the potential to harness the benefits of technology whilst also providing an aspect of play and entertainment which can enhance student enjoyment of and engagement with learning (Crocco, Offenholley, \& Hernandez, 2016).

\section{Serious games in healthcare training}

Within the field of health, serious games have been identified as providing an additional means of encouraging interest in training, education, and assessment of performance (Wattanasoontorn, Boada, Garcia, \& Sbert, 2013). Serious games for health are appearing in a number of contexts including emergency responders (Knight et al., 2010; Wade-Hahn, 2006), patient treatment adherence (Artioli, Berta, De Gloria, Pomicino, \& Secco, 2013; Hawn, 2009; Howell, 2005; Kost, 2001), professional education (Brunot-Gohin, Augeard, Aoun, \& Plantec, 2013), surgical procedures (Lewis, 2007; Marsh, 2012; Pasquier et al., 2016; Wattanasoontorn et al., 2013), and improving health-related knowledge and selfmanagement (Charlier et al., 2016). Much of the existing literature refers to the use of serious games for the support, psychoeducation, and raising of awareness of patients and healthcare consumers. This literature has indicated the value and efficacy of serious games for increasing health-related knowledge (Baranowski, Buday, Thompson, \& Baronowski, 2008; Fuchslocher, Niesenhaus, \& Kramer, 2011), increasing patient participation in health-related activities (Hawn, 2009), and increasing patient motivation and treatment adherence (Burke et al. 2009). In terms of literature regarding the use of serious games to train health 
practitioners, much of the activity has been in the realm of training more practical skills, such as those associated with surgical procedures (Graafland, Schraagen, \& Schijven, 2012; Sabri et al, 2010; Kato, 2010).

There is a paucity of literature on the use of serious games to teach professional clinical skills, suggesting this specific application within a health professional education context is novel. Studies which discuss the design process of serious games for clinical skills are also scarce, leaving a gap in the literature as to how such games can be created. Where studies discussing the design process have emerged, they have tended to be technical in nature and less accessible for those without a background in information technology (Raybourn, 2007; Westera, Nadolski, Hummel, \& Wopereis, 2008). In the instances where articles on serious game design are written for a broader audience, the focus tends to be on an element of design and does not take the reader through the process from idea conceptualisation to implementation and evaluation (Annetta, 2010; Van Eck, 2006; Yusoff, Crowder, Gilbert, \& Wills, 2009). This paper outlines the process of developing a serious game for trainee (provisional) psychologists for the support of teaching and learning core professional skills. In sharing their experience in developing a serious game for use in tertiary education, with no programming experience and no budget, through the engagement of students, the author outlines what may be a sustainable solution for undertaking the design and development of such learning activities.

\section{Theory to practice - The application of game design theory in a real-world example}

This paper demonstrates the application of game design theory and related technologies to provide a solution to the problem of teaching clinical skills in a postgraduate context. In an environment where staffing and resources are constrained, making solutions accessible to educators is of importance. Handheld devices are more pervasive in everyday life and it is recognised that the current technology can seem intimidating for educators that don't come from an IT background. The paper aims to build a model of educational game design for educators of all backgrounds. The model synthesises the theory of game design from conceptualisation to implementation and evaluation, building an accessible and transferable model, which to date has been replicated by the authors in psychology and dentistry. For the purposes of this paper, however, the experience in psychology is shared. The paper employs a combination of both participatory and programmatic design frameworks, providing a new lens for these frameworks that considers both an educator and user experience. The application of game design features demonstrates how the theory can be translated to practice, to create innovative solutions to real-world problems.

\section{Laurus - a learning platform}

This section describes, in detail, the approach used in the design and creation of the learning platform created, Laurus. The steps are illustrated in Figure 1.

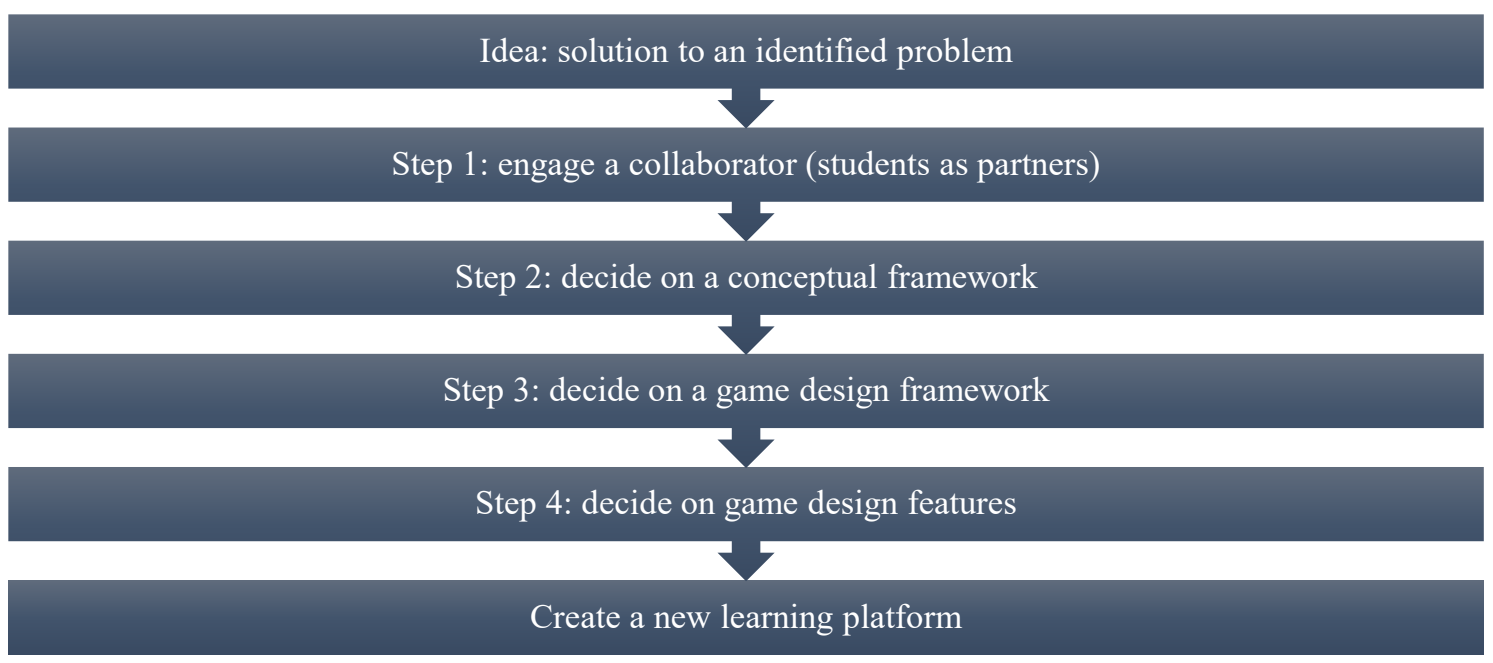

Figure 1. Flowchart of the game design process 


\section{Step 1 - Engage a collaborator}

As there was no budget, a consultant could not be engaged. This led to the necessity for some creative thinking. Following the emergence of the initial idea for the learning platform, the author approached the Game Design department of SAE Institute in Brisbane, Australia to contract final year games design students to design and develop the games as part of their final year project. Engaging students as partners is a sustainable solution for educators creating learning activities. This was a mutually beneficial relationship, as from a student perspective the project provided an opportunity to tackle a real-world challenge which added authenticity to the assessment task they were required to undertake. It also provided students with the experience of working with a real-world client. Research also indicates that student engagement in the creation of learning tasks enhances learning, retention, and achievement (Healey, O'Connor \& Broadfoot, 2010). A team of students including game designers, software programmers, a graphic artist, an audio specialist, and an animator was assembled to work with the author who undertook the role of content expert.

The planning and development of a serious game is complex and requires consideration of multiple criteria to ensure the game meets the need to be entertaining and appealing to end users whilst being effective at training skills and enhancing knowledge. The elements considered during the development of the Laurus games moved from broader conceptual frameworks inwards to finer considerations related to the actual game design and user experience. These frameworks and design considerations helped to guide the development of the games whilst navigating the balance between entertainment and education.

\section{Step 2 - Decide on a conceptual framework}

In planning Laurus games, the authors considered multiple levels of theoretical direction. On a broad level, experiential learning theory (ELT) was employed as a conceptual framework and guiding principle for what was being attempted (Kolb, 1984). The learning experience provided through the methodology of serious games can be understood through this theoretical framework, as ELT highlights the central role of experience in the process of learning. ELT conceives of learning as a process which involves cognitive, behavioural, perceptual and experiential aspects. The theory is thus holistic in its understanding of what constitutes learning. The theory proposes that the ideas themselves come from experience and are then, in turn, themselves shaped by further experience (Kolb, 1984).

Kolb (1984) conceptualised this cycle of learning as moving through four stages. At the outset, the learner engages in concrete experiences which then create observations stemming from the experience. The learner then reflects upon these observations. Thus, what were once abstract concepts, evolve through experiences and are then further tested through experimentation. This process of active experimentation and play with new experiences fosters learning (McCarthy, 2016; Smart \& Csapo, 2007). Serious games provide a sound basis from which experiential learning can occur (Crocco et al., 2016). Players can learn as they engage with the game, playing, failing (safely), and winning, just as would be experienced in a game played purely for entertainment purposes (Knight et al., 2010).

Through the process of engaging with the game, the students undertake an iterative process shifting between experience, reflection, and experimentation which generates an improved understanding and integration of the new knowledge acquired. It is also through this process of engaging directly with the knowledge that the students retain the information learned for longer (Kolb, 1984). As the student encounters the knowledge first hand, this contributes towards an authentic understanding of the material and changes in skill (Moon, 2005).

\section{Step 3 - Decide on a game design framework}

While ELT provided an overarching conceptual framework to guide the philosophical underpinnings of the development of Laurus, other design considerations and frameworks were employed to guide the design of the games themselves. These considerations are essential to creating a game which can provide an experience in which learning can take place. The Laurus games were created using a combination of both a programmatic/expert and participatory frameworks (Russ, 2010). The purpose of a programmatic approach is to communicate specific knowledge in a top-down manner, with the goal of generating the 
desired outcome, in this case, that of competent and qualified practitioners (Russ, 2010). In terms of the Laurus games, this can be understood as the communication of the key competencies, policies, guidelines, legislation, and procedures of the relevant professional bodies regulating the psychology profession. The expert content of the case scenarios used was based on the psychological competencies, guidelines, and policies for practice established by the Australian Psychological Accreditation Council (APAC), The Psychology Board of Australia (PsyBA), and The Australian Psychological Society (APS).

APAC sets the curriculum policies and guidelines which govern the core foundational competencies for all professional master's degree psychology programs in Australia. Based on these competencies, students entering a postgraduate higher degree in psychology at an Australian university undertake an orientation at the beginning of the course. The orientation program is designed to equip students with the key clinical skills necessary to begin their first field placement. Content covered includes but is not limited to, conducting an intake interview, conducting risk assessments, and ethical issues in psychological practice.

To ensure that the Laurus games are relevant and useful to the postgraduate students, a participatory approach was also incorporated in the game design and planning. A participatory approach prioritises the engagement of stakeholders, to facilitate their support of the project and to incorporate their knowledge and ideas into the final product (Russ, 2010). Throughout the development of Laurus, there were multiple points of engagement with key stakeholders.

Initially, a focus group was held with current Master of Psychology students at the University of Queensland. The students could articulate their experiences of training and the content that would have been most useful to them in the early stages of training. Students were also able to share which content areas they felt would be most useful in a serious games format as well as providing insight into their lifestyles and schedules to help assist designers to gain insight into how the game may be accessed and used by students. The game design students were present at the focus group to gain first-hand insight into the end users of the games. Following on from this, two user testing sessions were conducted with students and other stakeholders during the months of the development process. These testing sessions enabled the game designers to further understand how stakeholders engaged with and navigated the games. Academic and professional staff were also involved in the testing sessions which provided valuable input from other stakeholders. This use of the collective intelligence of students, academic and professional staff helped to define what the needs were and what would best support these as articulated by stakeholders (Clochesy et al., 2015).

This iterative developmental process demonstrates the participatory nature of the activity. End-user feedback was critical to the ongoing design of the serious games. The author and developers further found these testing sessions highly valuable in terms of understanding how the students engaged with the games and this, in turn, facilitated ongoing adaptation and development to meet student needs.

\section{Step 4 - Decide on design features}

Design features are critical to ensuring that engaging and successful games are developed (Brox, Fernandez-Luque \& Tollefsen, 2011; Lewis, 2007). The design elements considered in the development of Laurus are set out below in a table format, Table 1, as aligned to the work of Clochesy et al. (2015).

Table 1

Design considerations of Laurus

\begin{tabular}{|l|l|l|}
\hline Element & Considerations & Laurus implementation \\
\hline Experience & $\begin{array}{l}\text { Which problem- } \\
\text { solving strategies } \\
\text { were chosen? }\end{array}$ & $\begin{array}{l}\text { A role-playing style was used in three of the games, where } \\
\text { the player is required to select the correct dialogue to } \\
\text { progress through the game. The fourth game employed a } \\
\text { choose-your-own-adventure approach, where the player } \\
\text { has a quest of thinking of the correct responses to progress } \\
\text { (Schell, 2008). All the games utilise aspects of having to } \\
\text { drag and drop items into the correct place, as well as quiz } \\
\text { features (Brox, Fernandez-Luque, \& Tollefsen, 2011). }\end{array}$ \\
\hline
\end{tabular}




\begin{tabular}{|c|c|c|}
\hline $\begin{array}{l}\text { Facilitate } \\
\text { engagement } \\
\text { and immersion }\end{array}$ & $\begin{array}{l}\text { Graphics, animation, } \\
\text { and sound }\end{array}$ & $\begin{array}{l}\text { Laurus games used realistic looking 3-D images. These } \\
\text { images are rigged to allow for animation of movement in } \\
\text { future development. The clinic environment is also realistic } \\
\text { looking, including a reception/waiting room and } \\
\text { consultation rooms. The games use natural sounding, } \\
\text { varied, recorded voices with closed captioning, to } \\
\text { maximise the players' ability to follow the conversation. } \\
\text { These realistic aspects were employed to enhance the real- } \\
\text { life feeling of the games. Creating an immersing } \\
\text { experience has the potential to generate engagement with } \\
\text { the material and importantly to evoke emotion in the player } \\
\text { (Skalski \& Whitbred, 2010). Being in a state of emotional } \\
\text { arousal has benefits for the retention of information (Caine, } \\
\text { Caine, McClintic, \& Klimek, 2009). }\end{array}$ \\
\hline $\begin{array}{l}\text { Feedback and } \\
\text { reward } \\
\text { mechanisms }\end{array}$ & Immediate feedback & $\begin{array}{l}\text { An advantage of serious games in education is the ability to } \\
\text { provide players with immediate feedback (Brox et al., } \\
\text { 2011). Feedback in Laurus games is provided through } \\
\text { mechanisms such as the client's verbal responses to the } \\
\text { choices the players make, including anger and frustration } \\
\text { to incorrect choices. Other feedback mechanisms include } \\
\text { earning points and tokens for progression. At the end of } \\
\text { each scenario, players can view their overall performance } \\
\text { and receive feedback on what they did well and how they } \\
\text { may improve. Players are also able to see how they have } \\
\text { performed compared to other users. This element of } \\
\text { competition is another useful design consideration which } \\
\text { can enhance engagement (Brox et al., 2011). }\end{array}$ \\
\hline Levels of play & Multiple levels of play & $\begin{array}{l}\text { Each time a player completes a scenario, they progress to } \\
\text { the next client. As the levels progress, the clients present } \\
\text { with increasingly complex difficulties. This allows for } \\
\text { building on experience and helps to prevent boredom and } \\
\text { non-persistence (Gee, 2003). A highly useful feature for } \\
\text { games which provide health education is the ability to } \\
\text { provide a safe space in which to try, take risks and fail, } \\
\text { which is not feasible in real-world settings. The Laurus } \\
\text { games provide an environment in which students can take } \\
\text { risks, try new courses of action and experiment with what } \\
\text { may happen if they make the wrong choices. }\end{array}$ \\
\hline Evaluation & Game analytics & $\begin{array}{l}\text { Evaluation of a game's effectiveness is critical for future } \\
\text { success. To make evaluation a future possibility, the } \\
\text { analytics automatically collect data about use. Data } \\
\text { collected includes time spent playing and user choices. } \\
\text { This information is also useful for further game } \\
\text { development as well as for understanding where gaps in } \\
\text { student knowledge and skill exist. This can be used to } \\
\text { inform teaching. }\end{array}$ \\
\hline User interface & Ease of access & $\begin{array}{l}\text { Three of the Laurus games are available on mobile devices, } \\
\text { including smartphones and tablet. Both Android and iOS } \\
\text { versions were created. The fourth game was made for } \\
\text { PC/laptop use. The authors were interested in } \\
\text { understanding how players would access and use the games } \\
\text { and whether interface impacted on time spent playing the } \\
\text { games. For this reason, multiple interfaces were developed. }\end{array}$ \\
\hline
\end{tabular}


Figure 2, provides a visual representation of the various levels of theoretical consideration in developing the Laurus games.

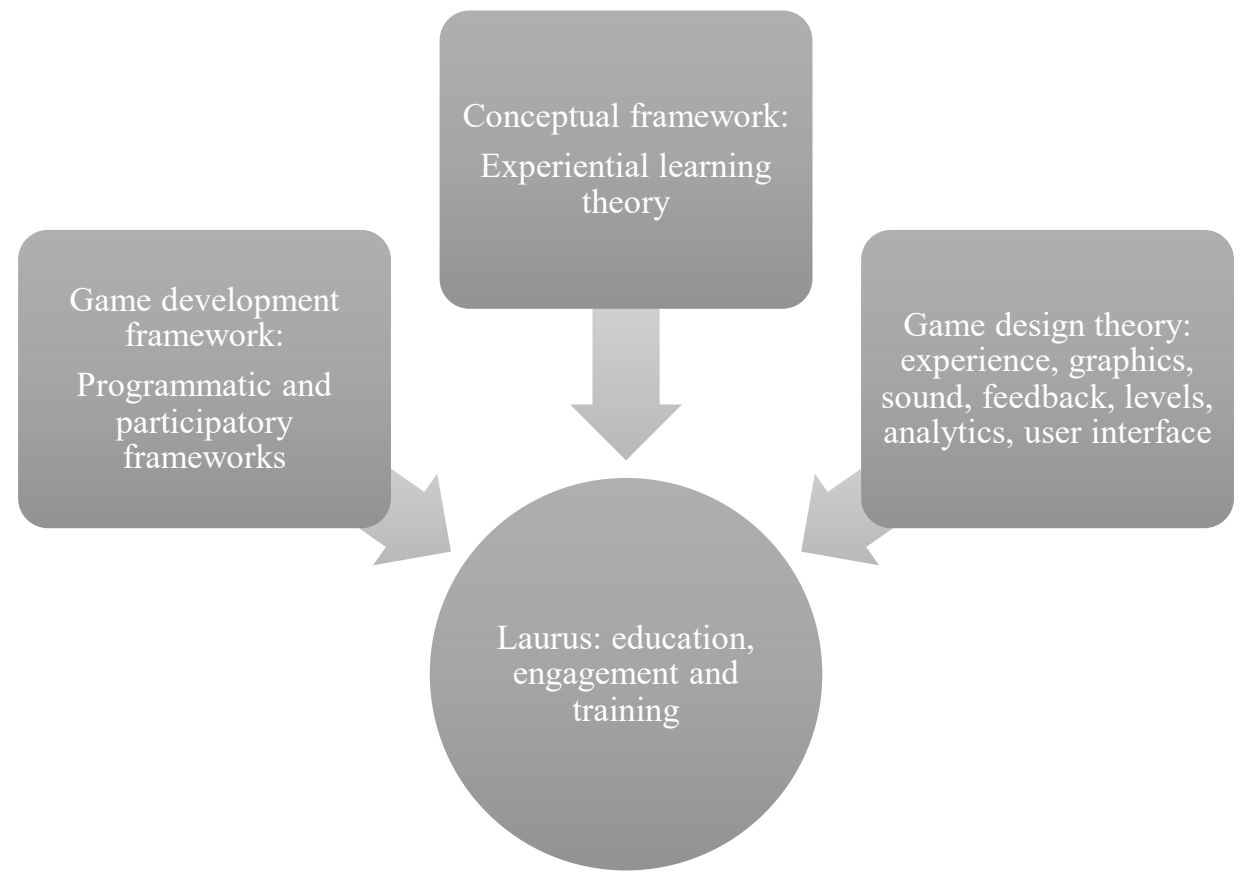

Figure 2. Model of development: Theoretical considerations

\section{Pilot study}

A pilot study was conducted to explore the efficacy of the serious games among provisional psychologists enrolled in the professional Master of Psychology degree at The University of Queensland (UQ), Australia.

\section{Method}

\section{Design, setting, and sample}

The pilot study used a mixed-methods, non-randomised, quasi-experimental approach. The comparative design was used to measure student anxiety levels, sense of preparation, and self-efficacy as related to professional practice on placement. Specifically, the study sought to explore whether engaging with the serious game impacted these factors significantly as compared to teaching as usual.

This study was conducted at UQ between May and June, during the first semester of 2016. A total of 43 students enrolled in the professional Master of Psychology degree, leading to registration as a psychologist, were invited to participate in the study. A sample of 42 participants was initially obtained from those students enrolled in the program. The final sample of participants included 37 students, as 5 participants failed to complete the post-test portion of the study and were excluded from the data analysis. The demographic characteristics of the sample are included in Table 2 below.

Participants were randomly assigned, using a computerised random number generator, to either one of two control groups or the experimental group. Control group $1(N=10)$ was to undertake teaching as usual in the program with no further intervention. Teaching as usual consisted of various courses covering content such as interpersonal and professional skills, foundations of psychological intervention, professional ethics, and psychopathology as well as an initial orientation over 2 days to skills such as risk assessment and record keeping. These latter skills are covered again in depth throughout the program. Control group $2(N=9)$ also undertook teaching as usual as well as being asked to download a memory game to their mobile device 
or personal computer. This unrelated game contained psychological principles commonly used in the assessment of memory and was used to control for the novelty effect of playing a game. The experimental group $(N=18)$ undertook teaching as usual and were given access to download the Laurus games (Risk Assessment, Ethical Dilemma, In Session [psychopathology] and First Session [intake interviewing]) to their mobile devices and personal computers. Students in the experimental group were provided with a link to a purpose-built webpage where they could download the games. Students were provided with instructions to play the games as often as possible over a 7-week period.

Table 2

Demographic characteristics of study 1 participants $(N=37)$

\begin{tabular}{ccc}
\hline \multicolumn{2}{l}{ Descriptor } & Sample \\
\hline Age (years) & \\
- & $20-25$ & $16(42 \%)$ \\
- & $26-35$ & $10(29 \%)$ \\
- & $36-45$ & $4(11 \%)$ \\
- & $46+$ & $7(18 \%)$ \\
Gender & & \\
- & Female & $31(85 \%)$ \\
- & Male & $6(15 \%)$ \\
\hline
\end{tabular}

\section{Measures}

Measurements sought to explore user experience by comparing pre and post-scores for confidence (selfefficacy), and readiness for practice across key clinical competencies. The study set out to measure the efficacy of the innovation as compared to teaching as usual, to determine whether the effort of the creation of the intervention translates to outcomes and if it has advantages over traditional models. The independent variable in the study was the Laurus games. Students in the experimental group were provided with access to the games in the first week of May in semester 1 of 2016. The dependent variables included the level of student anxiety experienced in relation to working with real-world patients on externship, feeling prepared for professional practice across key areas of competency, enjoyment of training, and engagement with learning material. Questionnaires were completed at the start of the study, prior to access to the Laurus games and then again after a 7-week period of exposure.

\section{Description of instruments}

Sample descriptors were used to collect data regarding students' age and gender. The State-Trait Anxiety Inventory (STAI) (Spielberger, Gorsuch, Lushene, Vagg, \& Jacobs, 1983) was utilised in both the pre and post-tests. The STAI is a reliable and valid instrument used to quantify adult anxiety. The STAI indicates a test-retest correlation .54 for the state anxiety scale and .86 for the trait anxiety scale (Spielberger, Gorsuch, Lushene, Vagg, \& Jacobs, 1970). The STAI consists of 40 Likert scale items and differentiates between anxiety as a trait, which is related to an individual's personality and how prone they are to anxiety, and anxiety as a state, which is the subjective experience of anxiety in response to a specific stressor. Participants were asked to rate their anxiety in relation to undertaking professional practice placement.

The Counselling Self Estimate Inventory (COSE) (Larson et al., 1992) was employed in the pre and posttests to measure trainee perceptions of their self-efficacy as therapists. The COSE reports an internal consistency of .93 and a 3-week test-retest reliability of .87 (Larson et al., 1992). The COSE is a 14 item Likert scale, self-report questionnaire, that measures trainee confidence in professional psychological skills including micro skills, attending to the process of the session, dealing with difficult client behaviour, being aware of ones' own values and being culturally aware.

A purpose built self-report questionnaire with Likert scale items was also utilised. This questionnaire utilised both positively and negatively phrased questions to explore student perceptions of how prepared they felt for practice, "I have had sufficient opportunity to practice the practical skills of being a psychologist"; enjoyment of the training process, "I have enjoyed the process of learning to apply theory in practice with clients"; and engagement with the study material, "I found the way these skills were taught and practiced engaging and interactive". The questionnaire also explored students' perceptions of their 
efficacy in terms of specific professional skills such as conducting an intake interview, assessing and diagnosing psychopathology, resolving ethical issues and adequately assessing risk of suicide and homicide, for example, "I feel competent to categorise a client's risk of harm", and "I feel confident to make the right decision to resolve an ethical dilemma".

\section{Procedure}

Prior to the commencement of the study, ethical approval was sought and granted, from the university's ethical review board. The study was then initiated by the externship coordinator who sent an email which explained the study and what participation would involve and sought participant consent. Student participation was voluntary. To be included in the study, participants were required to complete both a pretest and post-test questionnaire, the former prior to release of the serious game to the experimental group and the latter 7 weeks after the pre-test. The questionnaire included a section for descriptor information for demographics and the pre and post-test STAI, COSE, and the purpose-built questionnaire. To protect confidentiality students were asked to select a personalised code that was used on both the pre and posttest. Each questionnaire took approximately 15 minutes to complete. A reminder email was sent out to control group 2 and the experimental group at approximately 2 and 5 weeks into the study encouraging students to continue to play their assigned computer games as often as possible. Data analytics anonymously tracked student activity on the Laurus games, providing an indicator of student usage habits, including the length of play session and frequency of play. Questionnaires were completed online using Qualtrix. The data from this study is stored in a password-protected file on the primary researcher's online Qualtrix account and will be kept for a minimum of 5 years.

\section{Data analysis}

Descriptive statistical analyses, including the mean and standard deviation, were obtained for all data. As the samples were modest $(N=9, N=10$, and $N=18)$ the Shapiro-Wilk test was employed to test for normality. The $p$ values were greater than 0.05 level of significance and thus the null hypothesis was retained, and normality was assumed for the data. When comparing pre and post-test scores for each measure within a sample, paired-sample $t$-tests were utilised. For comparison of pre and post-test scores for each measure, between samples, independent sample $t$-tests were employed. Qualitative data was analysed using thematic analysis (TA) (Boyatzis, 1998). The answers to open-ended questions were analysed and arranged into themes which frequently occurred.

\section{Results and discussion}

The experimental group felt significantly better prepared for practice following exposure to the games, as compared to prior to the intervention (pre-test: $M=35.40, S D=4.517$ and post-test $M=26.40, S D=3.979$ ). The experimental group also indicated they enjoyed the process of learning more following exposure to the games $(t(14)=8.874, p=.021)$. No significant differences between the pre and post-test scores of the control groups were reported.

Students exposed to the games reported they felt significantly better prepared for practice $(M=26.40, S D$ $=3.979)$ compared to the control groups $(M=36.13, S D=7.434)$. The students using the games also reported that they enjoyed the learning process significantly more than the control groups reported $(t$ (28) $=-4.469, p=.001)$. No further significantly different results between the experimental and control groups were found.

Qualitative responses from the survey data provided useful information regarding how the students valued the experience and utilised the games in their own practice. The survey results indicated that students tended to value those games which covered content most closely related to their current level of professional development. They also adopted experiences from the games and applied these in practical competency assessments undertaken during the semester. The students valued the opportunity to practice in what they experienced as a safe environment, specifically, being able to safely explore what would happen if things went wrong and deliberately answering incorrectly to receive feedback, as this avenue is not available to them in real life practice. The exploration during the process of learning and the reported transfer of skills learned in the games to real-world practice indicate that the use of the games has potential implications for 
enhanced deep learning (Kolb, 1984). These preliminary observations appear positive and indicate that more extensive exploration and evaluation is necessary.

These results suggest that playing the Laurus games does have a positive effect on provisional psychologist's sense of feeling prepared for practice, having sufficient opportunity to practice new skills and enjoyment of the learning process. Specifically, our results suggest that Laurus games can help provisional psychologists feel better prepared for the practical component of the master's program and that they may be more effective in doing this than teaching as usual on its own.

These results support the idea that serious games in healthcare can enhance student engagement, motivation, and interest which can help form a sound basis from which learning can take place (Hagenauer \& Hascher, 2014). A teaching methodology which enhances the enjoyment of the process of learning has implications for improving retention of information and skills learned, as well as promoting authentic, successful, and quality learning (Coates, 2005; Crocco et al., 2016; Dror, 2008; Ferris \& Gerber, 1996). The implications of these findings suggest that serious games can help support the learning of new knowledge and skills, specifically in an environment characterised by high anxiety. These findings also suggest that serious games can positively support the transition to practice and the emergence of a professional identity, with potentially long-lasting positive implications for career trajectory and patient outcomes.

Several limitations of this study should be noted. The sample is admittedly small $(N=37)$ and the findings should be interpreted with some caution. Conducting this study with a larger sample, possibly across multiple universities which offer professional psychology master's degrees is suggested for future research. Another possible limitation relates to the study occurring in a real-world setting. The possibility must be acknowledged that control group participants may have had access or exposure at some level to the serious game. The student cohort of such programs is typically small and students spend a high volume of time together each day. As such, it must be conceded that some cross contamination is possible. To address this possibility, students were repeatedly reminded not to share the games. A further limitation concerns the measures used. Future research may benefit from including some measurement which does not rely on student self-report data which is at risk of biases related to factors such as exaggeration and selective bias. It would be valuable to collect data regarding student performance from sources including competence assessments, supervisor, and patient feedback reports. These methods of data collection are strongly recommended for future research. Finally, the research team was known to the students as part of the teaching staff involved in the program. This may have impacted on students' willingness to be honest, particularly with negative feedback. To address this all questionnaires were anonymous and completed via an online link. Despite these precautions, the possibility of a desire to please or fear of negative consequences resulting from negative feedback should be acknowledged, although qualitative data recorded suggests that students did provide negative feedback on several occasions. It is suggested that future research is undertaken at multiple universities where the research team will be unknown to the research participants.

\section{Conclusion}

Laurus games were developed to support the teaching and learning of professional psychological competencies for provisional psychologists undertaking a professional psychology master's degree. The design and development of the games were informed by multiple levels of theoretical consideration. A theoretically driven approach was undertaken to make the best effort at designing games that were simultaneously entertaining and engaging whilst being educational.

Key stakeholders were consulted throughout the developmental process to ensure user needs were met as well as to enhance support for the games. The expert content was incorporated into the games to ensure that they met curricula and educational requirements. Several design factors were considered, including the use of realistic game design elements to facilitate engagement with the games, elicit affective responses and ultimately enhance learning outcomes (Caine et al., 2009; Skalski \& Whitbred, 2010).

The development of this serious game for the training of health professionals can be understood as a process whereby a balance was sought between entertainment and educational factors. All principles and design considerations were required to contribute towards either or both factors. To create a serious game which 
manages to both entertain and educate or train players, it is critical to consider those elements in development and design which will build an experience for players. It is this experience which provides the foundation upon which learning can occur.

Results from the pilot study indicate that the group exposed to the intervention felt significantly better prepared for practice following exposure. Interestingly, the control group, undertaking teaching as usual, did not report a significant difference in preparedness for practice between pre and post-testing. The experimental group also reported feeling significantly better prepared for practice as compared to the control groups. The experimental group also enjoyed the process of learning significantly more when using the games, as well as significantly more than the control groups.

These results contribute to the growing body of work that advocates serious games for supporting teaching and learning, as well as in the space of training professional skills (Clochesy et al., 2015). The findings regarding enhanced enjoyment of the learning process are in line with the literature which suggests that serious games enhance student engagement with and receptivity to the material presented (Malone, 1980; Randel et al, 1992). This is of critical importance to facilitating deep learning and engagement of higherlevel cognitive processes (Trigwell \& Prosser, 1991). This active approach to learning promotes deep and authentic learning of material presented and enhances persistence, satisfaction and improved performance (Coates, 2005; Trowler, 2010).

The results from this initial pilot study, while modest, suggest that serious games can help provide meaningful practice opportunities of professional skills for provisional psychologists, as well as enhancing the enjoyment of the learning process (Gee, 2003; Susi, Johannesson, \& Backlund, 2007). This has implications for improving student experience of learning professional competencies. When students feel better prepared and are engaged in the learning process, outcomes are improved (Coates, 2005). The findings have implications for the encouragement of the use of such innovations in the education context. These types of solutions are becoming increasingly relevant as students become geographically dispersed and education faces a shift away from face-to-face pedagogies suggesting that these games can be useful for learning. This paper contributes to the growing body of evidence regarding the contribution and role of serious games in teaching and learning in healthcare.

\section{References}

Annetta, L.A. (2010). The "I's" have it: A framework for serious educational game design. Review of General Psychology, 14(2), 105-112. http://faculty.uoit.ca/kapralos/csci5530/Papers/mike1_design.pdf

Artioli, S., Berta, R., de Gloria, A., Pomicino, A., \& Secco, N. (2013). A serious game to inform about HIV prevention: HInvaders. A case study. In B. Schouten, S. Fedke, T. Berkker, M. Schijven, \& A. Gekker (Eds.), Proceedings of the 3rd European Conference on Gaming and Playful Interaction in Health Care (pp. 3-13). Amsterdam: Springer-Vieweg. https://link.springer.com/chapter/10.1007/9783-658-02897-8 1

Baranowski, T., Buday, R., Thompson, D.I., \& Baranowski, J. (2008). Playing for real: Video games and stories for health-related behaviour change. American Journal of Preventive Medicine, 34(1), 74-82. https://doi.org/10.1016/j.amepre.2007.09.027

Bergeron, B. P. (2006). Developing serious games. Hingham, MA: Charles River Media.

Boyatzis, R. E. (1998). Transforming qualitative information: Thematic analysis and code development. Thousand Oaks, CA: Sage.

Brox, E., Fernandez-Luque, L., \&Tollefsen, T. (2011). Healthy gaming - Video game design to promote health. Applied Clinical Informatics, 2(02), 128-142. https://www.ncbi.nlm.nih.gov/pmc/articles/PMC3631924/

Brunot-Gohin, C., Augeard, A., Aoun, A., \& Plantec, J. Y. (2013). Serious game based on Clinical cases: A multidisciplinary approach for self-assessment in dental education. In B. Schouten, S. Fedtke, T. Bekker, M. Schijven, \& A. Gekker (Eds.), Games for Health (pp. 163-172). Wiesbaden: SpringerVieweg.

Burke, J. W., McNeill, M. D. J., Charles, D. K. Morrow, P. J., Crosbie, J.H., \& McDonough, S. M. (2009). Optimising engagement for stroke rehabilitation using serious games. The Visual Computer, 25(12), 1085-1099. https://doi.org/10.1007/s00371-009-0387-4 
Caine, R. M., Caine, G., McClintec, C., \& Klimek, K. J. (2009). 12 Brain/mind learning principles in action (2nd ed.). Thousand Oaks, CA: Corwin Press.

Charlier, N., Zupancic, N., Fieuws, S., Denhaerynck, K., Zaman, B., \& Moons, P. (2016). Serious games for improving knowledge and self-management in young people with chronic conditions: a systematic review and meta-analysis. Journal of the American Medical Informatics Association, 23, 230-239. https://doi.org/10.1093/jamia/ocv100

Clochesy, J. M., Buchner, M., Hickman Jnr, R. L., Pinto, M. D., \& Znamenak, K. (2015). Creating a serious game for health. Journal of Health and Human Services Administration, 38(2), 162-173. https://www.jstor.org/stable/24463889

Coates, H. (2005). The value of student engagement for higher education quality assurance. Quality in Higher Education, 11(1), 25-36. https://doi.org/10.1080/13538320500074915

Crocco, F., Offenholley, K., \& Hernandez, C. (2016). A proof-of-concept study of game based learning in higher education. Simulation \& Gaming, 47(4), 403-422. https://doi.org/10.1177/1046878116632484

De Stefano, J., D’Iuso, N., Blake, E., Fitzpatrick, M., Drapeau, M., \& Chamodraka, M. (2007). Trainees experiences of impasses in counselling and the impact of group supervision on their resolution: A pilot study. Counselling and Psychotherapy Research, 7(1), 42-47. https://doi.org/10.1080/14733140601140378

Dror, I. E. (2008). Technology enhanced learning: The good, the bad, and the ugly. Pragmatics \& Cognition, 16(2), 215-223.

http://nebula.wsimg.com/644a07a472f027fb6bea6dc189dc30a4?AccessKeyId=09634646A61C4487D FA0\&disposition $=0$ \&alloworigin $=1$

Ferris, J., \& Gerber, R. (1996). Mature-age students' feelings of enjoying learning in a further education context. European Journal of Psychology of Education, 11(1), 79-96. https://doi.org/10.1007/BF03172937

Fuchslocher, A., Niesenhaus, J., \& Kramer, N. (2011). Serious games for health: An empirical study of the game "Balance" for teenagers with diabetes mellitus. Entertainment Computing, 2(2), 97-101. https://doi.org/10.1016/j.entcom.2010.12.001

Gee, J. P. (2003). What video games have to teach us about learning and literacy. New York, NY: Palgrave MacMillan.

Graafland, M., Schraagen, J. M., \& Schijven, M. P. (2012). Systematic review of serious games for medical education and surgical skills training. British Journal of Surgery, 99(10), 1322-1330. https://doi.org/10.1002/bjs.8819

Hagenauer, G., \& Hascher, T. (2014). Early adolescents' enjoyment experienced in learning situations and its relation to student achievement. Journal of Education and Training Studies, 2(2), 20-30. http://www.redfame.com/journal/index.php/jets/article/viewFile/254/268

Hawn, C. (2009). Games for health: The latest tool in the medical care arsenal. Health Affairs, 38(5), 824848. https://doi.org/10.1377/hlthaff.28.5.w842

Healey, M., O’Connor, K. M., \& Broadfoot, P. (2010). Reflections on engaging students in the process and product of strategy development for learning, teaching and assessment: an institutional case study. International Journal for Academic Development, 15(1). https://doi.org/10.1080/13601440903529877

Howard, E. E., Inman, A. G., \& Altman, A. N. (2006). Critical incidents among novice counsellor trainees. Counsellor Education and Supervision, 46(2), 88-102. https://doi.org/10.1002/j.15566978.2006.tb00015.x

Howell, K. (2005). Games for Health Conference 2004: Issues, trends and needs unique to games for health. Cyber Psychology \& Behaviour, 8(2), 103-109. https://doi.org/10.1089/cpb.2005.8.103

Kato, P. M. (2010). Video games in healthcare: Closing the gap. Review of General Psychology, 14(2), 113-121. https://pdfs.semanticscholar.org/1af2/783f7c977fbaab98203f11d48446f33e8cea.pdf

Klauer, K. J., \& Leutner, D. (Eds.). (2012). Teaching and learning: Introduction to instructional psychology (2nd ed.). Weinheim: Beltz.

Kolb, D. A. (1984). Experiential learning: Experience as the source of learning and development. Englewood Cliffs, NJ: Prentice Hall.

Knight, J. F., Carley, S., Tregunna, B., Jarvis, S., Smithies, R., de Freitas, S., \& Mackway-Jones, K. (2010). Serious gaming technology in major incident triage training: a pragmatic controlled trial. Resuscitation, 81(9), 1175-1179. https://doi.org/10.1016/j.resuscitation.2010.03.042

Kost, G. (2001) Preventing medical errors in point-of-care testing: Security, validates, safeguards, and connectivity. Archives of Pathology \& Laboratory Medicine, 125(10), 1307-1315. https://doi.org/10.1043/0003-9985(2001)125\%3C1307\%3APMEIPO\%3E2.0.CO\%3B2 
Larson, L. M., Suzuki, L. A., Gillespie, K. N., Potenza, M. T., Bechtel, M. A., \& Toulouse, A. L. (1992). Development and validation of the counseling self-estimate inventory. Journal of Counseling Psychology, 39(1), 105-120.

Lewis, M. W. (2007). Analysis of the roles of "serious games" in helping teach health-related knowledge and skills and in changing behavior. Journal of Diabetes Science and Technology, 1(6), 918-920. http://journals.sagepub.com/doi/pdf/10.1177/193229680700100618

Malone, T. W. (1980). What makes things fun to learn? A study of intrinsically motivating computer games. (Doctoral dissertation.) Stanford University, Stanford, CA.

Marsh, T. (2012, October 11). Serious games are becoming serious business. Australia Business Review. http://www.businessreviewaustralia.com/technology/1108/Serious-Games-Are-Becoming-SeriousBusiness

Mautone, T., Spiker, V., \& Karp, D. (2008). Using serious game technology to improve aircrew training. Proceedings of the Interservice/Industry Training, Simulation and Education Conference (IITSEC) Orlando, FL.

https://www.interplaylearning.com/hubfs/Blog/Case\%20Studies/Using\%20Serious\%20Game $\% 20 \mathrm{Tec}$ hnology \%20to\%20Improve\%20Aircrew\%20Training\%20(1).pdf?t=1531486526396

McCarthy, M. (2016). Experiential learning theory: From theory to practice. Journal of Business \& Economic Research, 14(3), 91-100.

Melton, J. L., Nofzinger-Collins, D., Wynne, M. E., \& Susman, M. (2005). Exploring the affective inner experiences of therapists in training: The qualitative interaction between session experience and session content. Counsellor Education and Supervision, 45(2), 82-96. https://doi.org/10.1002/j.15566978.2005.tb00132.x

Mendl, M. (1999). Performing under pressure: Stress and cognitive function. Applied Animal Behaviour Science, 65(3), 221-244. https://doi.org/10.1016/S0168-1591(99)00088-X

Moon, J. A. (2005). A handbook of reflective and experiential learning: Theory and practice. London: Routledge Falmer.

Pasquier, P., Merat, S., Malgras, B., Petit, L., Queran, X., Bay. C. ... Perez., J.P. (2016). A serious game for massive training and assessment of French soldiers involved in forward combat casualty care (3DSC1): Development and deployment. JMIR Serious Games, 4(1), e5. https://doi.org/10.2196/games.5340

Randel, J. M., Morris, B. A., Wetzel, C. D., \& Whitehall, B. V. (1992). The effectiveness of games for educational purposes: A review of recent research. Simulation \& Gaming, 23(3), 261-276. https://doi.org/10.1177/1046878192233001

Raybourn, E. M. (2007). Applying simulation experience design methods to creating serious game-based adaptive training systems. Interacting with Computers, 19(2), 206-214.

https://academic.oup.com/iwc/article-abstract/19/2/206/696314/Applying-simulation-experiencedesign-methods-to

Ricciardi, F., \& De Paolis, L. T. (2014). A comprehensive review of serious games in health professions. International Journal of Computer Games Technology, 2014. https://doi.org/10.1155/2014/787968

Russ, T. L. (2010). Programmatic and participatory: Two frameworks for classifying experiential change implementation methods. Simulation \& Gaming, 41(5), 767-786. https://doi.org/10.1177/1046878109353570

Sabri, H., Cowan, B., Kapralos, B., Porte, M., Backstein, D., \& Dubrowskie, A. (2010). Serious games for knee replacement surgery procedure education and training. Procedia-Social and Behavioral Sciences, 2(2), 3483-3488. https://faculty.uoit.ca/kapralos/publications/wces2010_knee.pdf

Schell, J. S. J. (2008). The art of game design. Burlington, MA: CRC Press.

Skalski, P., \& Whitbred, R. (2010). Image versus sound: A comparison of formal feature effects on presence and video game enjoyment. PsychNology Journal, 8(1), 37-84.

Skovholt, T. M., \& Ronnestad, M. H. (2003). The journey of the counsellor and therapist: Research findings and perspectives on professional development. Journal of Career Development, 30(1), 5-44. https://doi.org/10.1177/089484530303000102

Smart, K. L., \& Csapo, N. (2007) Learning by doing: Engaging students through learner-centered activities. Business Communication Quarterly, 70(4), 451-457.

Spielberger, C. D., Gorsuch, R. L., Lushene, R. E., Vagg, P. R., \& Jacobs, G. A. (1970). STAI manual for the state-trait anxiety inventory. Palo Alto, CA: Consulting Psychologists Press.

Spielberger, C. D., Gorsuch, R. L., Lushene, R. E., Vagg, P. R., \& Jacobs, G. A. (1983). Manual for the state-trait anxiety inventory. Palo Alto, CA: Consulting Psychologists Press. 
Stokes, B. (2005). Video games have changed: Time to consider, serious games. The Development Education Journal, 11(3), 12.

Susi, T., Johannesson, M., \& Backlund, P. (2007). Serious games - An overview. (Technical Report HSIKI-TR-07-001). Sweden: School of Humanities and Informatics University of Skovde.

Trigwell, K., \& Prosser, M. (1991). Improving the quality of student learning: The influence of learning context and student approaches to learning on learning outcomes. Higher Education, 22(3), 251-266. https://doi.org/10.1007/BF00132290

Trowler, V. (2010). Student engagement literature review. The Higher Education Academy, 11(1), 1-15.

Van Eck, R. (2006). Digital game-based learning: It's not just the digital natives who are restless. Educause Review, 41(2), 1-16.

Wade-Hahn, C. (2006). Serious game teaches emergency responders. Federal Computer Week, 20(18), 52-54.

Wattanasoontorn, V., Boada, I., Garcia, R., \& Sbert, M., (2013). Serious games for health. Entertainment Computing, 4(4), 231-247. https://doi.org/10.1016/j.entcom.2013.09.002

Westera, W., Nadolski, R. J., Hummel, H. G. K., \& Wopereis, I. G. J. H. (2008). Serious games for higher education: A framework for reducing design complexity. Journal of Computer Assisted Learning, 24(5), 420-432. https://doi.org/10.1111/j.1365-2729.2008.00279.x/full

Yusoff, A., Crowder, R., Gilbert, L., \& Wills, G. (2009). A conceptual framework for serious games. Proceedings of the Ninth IEEE International Conference on Advanced Learning Technologies, Riga, Latvia. http://eprints.soton.ac.uk/171663/

Corresponding author: Gillian McGregor, g.mcgregor1@uq.edu.au

Australasian Journal of Educational Technology (C) 2019.

Please cite as: McGregor, G., \& Bartle. E. (2019). The creation and trial of a serious game to support teaching and learning of professional psychology competencies in postgraduate programs. Australasian Journal of Educational Technology, 35(5), 15-28. https://doi.org/10.14742/ajet.4237 